\title{
II. TOWARD A THEORY ON CONSCIOUSNESS BASED ON RECENT DEVELOPMENTS IN SUBLIMINAL RESEARCH
}

\author{
HOWARD SHEVRIN
}

\section{INTRODUCTION}

In this paper I will be presenting the thesis that one of the most important questions in contemporary psychology and neuroscience concerns the relationship between conscious and unconscious processes. It will be my contention that consciousness cannot be fully understood without a concomitant understanding of unconscious processes, and that unconscious processes cannot be fully fathomed without an understanding of conscious processes. It will be my further contention that this conjoint understanding can only be achieved by placing individuality at the heart of the solution. It is widely accepted by consciousness theorists that subjectivity is the hallmark of consciousness. Subjectivity by definition is always individual. From the standpoint to be developed in this contribution, there cannot be a completely free standing theory of consciousness without taking the unconscious into account, or a theory of the interaction between conscious and unconscious processes without taking individual differences into account. It follows from this position that any quantitative or qualitative differences between conscious and unconscious processes can best be seen through the lens of individual differences. Methods must be devised to study conscious and unconscious processes jointly as a function of these individual differences. I will be describing a number of studies that illustrate this position.

Until recently the interaction of conscious and unconscious processes would not have been of interest to psychologists and neuroscientists. For half of the twentieth century psychology was denying the relevance of consciousness to a scientific psychology, and for several more decades it disputed the existence of unconscious processes. A decade before the turn of the twentieth century, James published ten arguments against the concept of an unconscious, the last argument leveled at the existence of unconscious motivation (James 1890). Not long afterwards, Watson ruled consciousness out of bounds for scientific investigation. In an ironic footnote to history, Watson's famous Alfred experiment was intended to provide experimental evidence for the psychoanalytic theory of childhood phobias. To my knowledge this experiment was the high 
water mark of Watson's flirtation with psychoanalysis. Following Watson, Skinner emerged as the foremost figure in psychology. For Skinner the notion of a mental life, conscious or unconscious, was subject matter for literature and not for science. He also rejected the relevance of neuroscience to psychology. Of the leading figures of twentieth century psychology it was only Freud who upheld the importance of a mental life grounded in the brain and characterized by interacting conscious and unconscious processes in which feeling and desiring in all its forms occupied an important place alongside perceiving, remembering, and thinking. Equally important to Freud was the importance of personal history and the unique contexts in which individual experience occurs; psychoanalytic theory in large part emerged out of clinical experience with individual patients. In this regard it is of interest that only recently have models of brain functioning begun to appear which posit highly interactive neuronal systems in which individual differences, context and history are essential factors (Edelman 1987; Friston 2000). Similarly, in an official report of the American Psychological Society, the home of most American cognitive scientists, Brewer and Luce (1998) strongly recommended that future cognitive research incorporate individual differences and context.

As we begin the twenty-first century the challenge to psychology and neuroscience is to create vibrant, real to life explanations of how the brain/mind organization works. The programmatic Freudian perspective on the mind in its broadest essentials can be of assistance in this task. As Kandel (1999) has observed with respect to the current status of psychiatry that could apply as easily to psychology and neuroscience, psychoanalysis offers, for all its limitations, the only comprehensive theory we have. At the same time, psychoanalysts must see beyond the narrow boundaries of their clinical enterprise to the broader horizons envisioned by Freud's comprehensive theory of mind, and embrace the necessity for empirical and experimental methods, along with greater rigor of systematic thinking.

To better capture the essence of what I wish to convey I will start with a metaphor. Imagine a stage on which a play is being produced, in some ways different from Dr. Baars' Theater of Consciousness (1997). The actors deliver their lines, interact with each other, and then exit singly or severally, as the plot unfolds. In the ordinary theater the actors exit into the wings to have a cup of coffee, change costumes, or they rehearse their next lines and otherwise prepare themselves for their return on stage. But in my theater they are never off stage. When they exit 
one stage they enter on to a new stage hidden from the audience and the other actors where they continue to interact with each other. The audience in front of the visible stage is unaware of this other stage, while the actors you see come and go from one stage to the other are only partially aware of what has been happening on the invisible stage. Yet what is happening on it will greatly determine what happens next in the play. When the actors now reenter from the hidden stage, sometimes on cue, sometimes not, they are saying things and reacting to the other characters in ways that are puzzling and disconcerting to the other actors and to the audience. But being seasoned actors and theatergoers they try to paper over these disconnections and disruptions and maintain some sense of continuity. Nevertheless there is much that is happening on stage that is mystifying and at times disorganized, replete with elisions, omissions, and seemingly out of place speeches and actions, a kind of theater of the absurd.

I first presented this analogy in discussion remarks at a CIBA conference on consciousness (Bock \& Marsch 1993). To my surprise, some years later the British playwright, Alan Ayckbourn wrote two plays with the same actors to be performed simultaneously on two stages, one play taking place indoors and the other in an adjacent garden outdoors. The plays were called Home and Garden (2000). When the actors exited from one stage it was to enter the second stage, and what happened before and after on either stage influenced the action seen by the two separate audiences. Playgoers were encouraged to see both plays so that they would have a complete appreciation of what was going on separately on each stage. In my analogy the one play was the unconscious for the other.

There are several points I wish to make by way of this theater analogy:

1. Consciousness cannot be fully understood without knowledge of what is going on unconsciously. The audience in my metaphor cannot finally understand what is going on before them without knowing about the events occurring on the other invisible stage.

2. What is going on unconsciously is as complex and representational as what is going on consciously. It is not the case that unconscious processes are essentially part processes that are only integrated consciously, or that they are purely physiological and it is only with consciousness that the truly mental in Brentano's sense of possessing intentionality appears, nor is the unconscious purely dispositional or latent. The actors on my invisible stage are as real as the actors on the 
visible stage, in fact they are the same actors, their lines are as meaningful, and their actions are as consequential.

3. The interactions between conscious and unconscious processes are always taking place at a specific time, in a particular place, and in one person only whose history invests with particularity the form and content of the interaction. Thus the interaction cannot be understood apart from context. My play on two stages deals with particular events in the lives of particular people. The play itself is the expression of one mind and the product of one brain.

4. Governing the interaction between conscious and unconscious processes are certain regularities that emerge out of the individual instantiation of these interacting processes. These differences are of a quantitative and qualitative nature, as I will try to illustrate from our research.

Mainly I will be concentrating my remarks on quantitative and qualitative differences in the interaction of conscious and unconscious processes because these differences will allow me to illustrate the other points just described as well. In this short chapter I will describe these views in schematic form, although I will refer to former published reports or research in progress that I and my colleagues have conducted in support these views. Among these colleagues are Drs. Linda Brakel, Michael Snodgrass, William Williams, Ramesh Kushwaha, Selin Aviyente, Edward Bernat, Scott Bunce, Philip Wong, Karen Villa, Shasha Kleinsorge, John Hartman, Richard Hertel, and James Bond. Our group is interdisciplinary, made up of psychologists, psychoanalysts, psychiatrists, and biosignal analysts.

\section{QUANTITATIVE RELATIONSHIPS BETWEEN CONSCIOUS AND UNCONSCIOUS PROCESSES}

To return to the theatrical analogy, and if I may strain it to the breaking point, the reason the "unconscious" stage remains unknown to the audience is that the action on it is carried out in whispers. In short, there is a quantitative factor that is the best researched property of unconscious processes, at least for those unconscious processes investigated with subliminal stimuli. Stimulus energy has a good deal to do with whether a stimulus will become conscious or not. Yet this is not the whole story. Our research has shown that there is a complex relationship between stimulus energy and different kinds of thresholds that have 
quite different implications for the relationship of the stimulus to consciousness.

By way of introduction to this point let me show you a plot of eventrelated potentials to the same stimuli presented subliminally and supraliminally. At first glance the subliminal curve appears to be a flat line as compared to the noticeable amplitude fluctuations in the supraliminal curve. However, if you simply multiplied each point on the subliminal curve by a factor of four, the resultant curve is markedly similar in structure to the supraliminal curve. In fact, the cross-correlations at a number of electrodes are quite substantial and highly significant statistically. In other words, the processes going on unconsciously are similar to those going on consciously; they differ solely in their strength, or in this case, in their voltage amplitude. (This plot was published in a paper by Bernat, Bunce and Shevrin in the International Journal of Psychophysiology in 2001 as part of a study of unconscious affect).

But the full story about stimulus intensity is more complicated and interesting. In a searching methodological and theoretical examination of subliminal research Dr. Snodgrass in collaboration with Dr. Bernat and myself in a paper to be published in Perception and Psychophysics (2005) concluded that much recent subliminal research is conducted at the subjective threshold. At this threshold phenomenal consciousness is present despite the subject's avowal that only guessing is involved. We distinguish between phenomenal and reflective consciousness, the latter involving an awareness of being aware whereas the former does not. This is similar to the distinction made by Edelman (1987) between primary and secondary consciousness, and Block (1995) between phenomenal consciousness and access consciousness. At the subjective threshold the stimulus conditions fail to meet the criteria for reflective awareness but phenomenal awareness is present. The stimuli are thus not truly unconscious.

Another way of describing this distinction can be drawn from signal detection theory. At the subjective threshold d', or stimulus detectability, is significantly above zero, but the avowed absence of consciousness is a function of the subject's criterion for what is deemed sufficiently clear to be accepted as conscious. Or otherwise put, the subject reflects on, or judges whether a given impression in phenomenal consciousness meets the subject's personal criterion for consciousness. By contrast, there is a body of subliminal research, including our own studies that have been conducted below the objective detection threshold. At the 
objective detection threshold d' is at zero, no phenomenal consciousness of the stimulus is present.

Of great relevance to the relationship of conscious and unconscious processes is the finding that a different relationship exists between stimulus detection, d', and the purported subliminal effects at the subjective and objective thresholds. (In most subliminal studies the test for subliminality is administered after the assessment of a subliminal effect on some task has been obtained). At the subjective threshold a positive relationship exists between d' and the purported stimulus effect: The more sensitive the subject is to the stimulus on the detectability task, the greater the subliminal effect. This is exactly what one would expect if the stimulus were in phenomenal consciousness. It is quite otherwise at the objective detection threshold. The relationship is negative (Bernat, Shevrin \& Snodgrass 2001; Snodgrass, Shevrin \& Kopka 1993). The greater the sensitivity to the stimulus, the weaker the subliminal effect. Here there seems to be a curious relationship between a measure of stimulus detectability and whether or not a subliminal effect is strong or weak.

At first glance it might appear that if even a smidgen of consciousness were present this would serve to inhibit subliminal effects. In fact, under certain conditions some consciousness can inhibit subliminal effects. This is particularly true at the objective identification threshold at which subjects can consciously see something but not enough to correctly identify the stimulus as a particular word, for example; subliminal effects tend to disappear under these conditions. Snodgrass (2005b) has developed a nonmonotonic theory to explain these relationships between consciousness and subliminal effects.

But at the objective detection threshold it is difficult to believe that a d' slightly above zero and falling well within a chance distribution around zero would reflect any degree of consciousness. Moreover, statistical analysis reveals that there are no outliers. And yet there must be something systematic in these individual fluctuations above and below the d' mean or we would not have found the negative correlations in more than one study.

The possibility suggests itself that we are dealing with individually determined changes in unconscious processing that have different consequences for what will enter consciousness as the response to a subliminal stimulus. In a series of studies we found that when subjects were asked to guess which of four words was flashed subliminally at the objective detection threshold ( $1 \mathrm{msec} ; 5 \mathrm{ft} / \mathrm{lamb})$, the main effect was at 
chance; the proportion of correct guesses was not significantly different from $25 \%$. However, we had also built into the experiments two other factors: 1 . task strategy, and 2. task preference. Task strategy took two forms: a "pop" strategy in which subjects were asked to let one of the four words "pop" into mind, and a "look" strategy in which subjects were asked to look as carefully as possible and to base their guesses on what they thought they saw. Subjects were also asked which of the two strategies they preferred. About thirty to forty percent preferred the "look" strategy.

Once strategy and preference were introduced taken into account, rather striking findings emerged: In seven experiments, two conducted in another laboratory (Van Selst \& Merikle 1993), we discovered a consistently significant interaction between strategy and preference (Snodgrass, Shevrin \& Kopk 1993). Of particular interest were the "look" preference subjects. In the "pop" strategy they performed significantly below chance while in the "look" strategy they performed significantly above chance. The "pop" preference subjects showed the opposite pattern, but more weakly. Clearly if you were to add up performance in the two strategies you would end up with zero subliminal effect.

Now it could be argued that the "look" subjects became conscious of the stimulus when the strategy fit with their preference, hence they performed above chance in the "look" strategy. If that were the case we should expect to find a positive correlation between d' and their correct guesses. It was quite otherwise. The correlation was significantly negative. Any individual increase in d' worked against improvement in their guesses. In fact, the negative correlation suggests that a below chance d' enhances guessing performance. And if we bear in mind that unconscious processes are involved whether a score is above or below the d' mean, we can see how there must be individually determined fluctuations in unconscious processing that exercise inhibitory or facilitating effects on what enters consciousness.

It is perhaps not accidental that the subjects who show the below chance performance in the "pop" condition are "lookers". These are people to whom seeing what is there is important and who are not disposed to letting things just "pop" into their heads. Since nothing is really there to be seen consciously, they inhibit unconsciously the correct responses. The stake these subjects have in maintaining a coherent conscious experience results in diminishing their unconscious performance. I offer this as an example of how conscious and unconscious processes 
interact as a function of individuality (strategy preference) and context (task strategy).

In the same series of experiments we also have evidence that defensive operations in the psychoanalytic sense may be involved. The Hysteroid-Obsessoid Questionnaire (HOQ) is a personality inventory devised to identify hysterical patients on the one extreme and obsessive patients on the other extreme (Caine \& Hawkins 1963). From other research we have reason to believe that the scale also correlates with a tendency to use repression as a defense (Ludolph 1981). It turns out that subjects high in repression show the same pattern as "lookers". They inhibit in the "pop" condition and facilitate in the "look" condition. Nevertheless, and perhaps surprisingly, "lookers" and "repressors" are not the same people. The two factors are unrelated to each other. The repression finding points to another individual difference playing a role in how subliminal stimuli are processed and what is permitted into consciousness. One could not determine from the below or above chance performance alone whether it was look preference or repression that produced the results.

The relationship between repression and consciousness has been explored in another study recently published by Libet, Ghannam, and myself (2002). This study took as its point of departure Libet's well known finding that it takes on average of $500 \mathrm{msec}$ for a stimulus to become conscious (Libet, Alberts, Wright et al. 1964). What is not as well known is that subjects vary from 200 to $800 \mathrm{msec}$ in the time for a stimulus to become conscious. What might be going on during this varying time interval? We reasoned that this individual difference might constitute a necessary condition for repression. People who took a longer time to become conscious would be more likely to use repression as a defense. We tested this hypothesis by administering this same Hysteroid-Obsessive Quesionnaire to Libet's subjects whose time varied from 200 to $750 \mathrm{msec}$. We found as hypothesized that longer time to consciousness was associated with greater repressiveness. This finding suggests that an individual characteristic of consciousness contributes to the selection of a particular defense, another instance of the way conscious and unconscious processes interact as a function of individual differences.

However, there is a problem in too hastily concluding that repression is involved in the studies just described. The psychoanalytic theory of repression requires that the stimuli have personal and unconscious 
conflictual significance. The stimuli in neither the pop/look studies nor the time to consciousness study met these three criteria. In another study we undertook to meet these criteria, an initial report of which was published in Consciousness and Cognition (Shevrin, Williams, Marshall et al. 1992), and a final book length report some time thereafter (Shevrin, Bond, Brakel et al. 1996). In this study a team of psychoanalysts examined interview transcripts conducted with patients suffering from social phobias. They then arrived at a hypothesis concerning the unconscious conflict causing the social phobia in each patient. Parenthetically, I should note in keeping with the thesis of this contribution that the conflicts were as various as the patients. On the basis of this hypothesis the team of psychoanalysts selected words or brief phrases they believed were significantly related to the unconscious conflict. In addition, words were selected that captured the patient's conscious experience of the phobia, as well as two control categories made up of unrelated negative and positive affect words. These four sets of words were then presented subliminally (below the objective detection threshold) and supraliminally, while at the same time event-related potential brain responses were obtained to each stimulus.

There were two findings of interest: 1 . when the stimuli related to the hypothesized unconscious conflict were presented subliminally the brain responses differentiated them from the other three sets of stimuli, but when the same unconscious conflict stimuli were presented supraliminally the brain responses no longer differentiated them from the other sets of stimuli, 2. the difference between successful differentiaton subliminally and the failure to differentiate supraliminally was positively correlated with the Hysteroid-Obsessiod Questionnaire. The more repressive the patient the greater the difference in favor of subliminal differentiation of the unconscious conflict stimuli. This relationship was not found for the words related to the conscious symptom experience, which as one might expect were better differentiated supraliminally.

Taken together these findings support the inference that repression must have been involved. The words had been selected in advance by a team of psychoanalysts who hypothesized that they were related to the presumed unconscious conflict, these words were highly personal (a point I shall return to), and they were presented out of consciousness, thus meeting the three criteria for repression. And independently supporting this inference was the correlation with the Hysteroid-Obsessoid Questionnaire. 
As I just mentioned, the words were highly personal. Unlike most psychological experiments, including some of our own like the pop/look studies, the verbal stimuli used were unique for each subject. This was particularly true for the words related to the unconscious conflict. Nevertheless, the same functional relationships were found across subjects. I cite this as an example of how taking individuality into account need not leave us with idiosyncratic ideographic data lacking in generalizability, but rather constitutes the only way that certain general principles can be discovered. In this instance the general principle concerns the operation of defenses with respect to unconscious conflict. But I suggest that when dealing with the interaction between conscious and unconscious processes unless individuality is taken into account important principles will go undiscovered. The time to consciousness discovered by Libet is certainly of general interest, but as our study showed it is remarkably sensitive to individual differences. We have evidence from other studies as well that personality factors are especially important when dealing with unconscious processes as these interact with consciousness. The pop/look studies are good examples of this principle.

The major limitation, however, of the studies just described is that they do not help us to identify the mechanism of repression. The time to consciousness study describes a necessary by not sufficient condition for repression. The pop/look and social phobia study provide purely correlational evidence. There is one study currently under way conducted by Brakel, Kushwaha, Snodgrass, and myself that at least begins to point in the right direction for finding such a mechanism. In a study of spider phobics who were given a signal detection test for drawings of spiders below the objective detection threshold we found that, unlike snake phobics who were shown the same spider stimuli, the brain response at the vertex was greater than at the occiput. Secondly, the same HOQ correlated negatively with spider detectability for the spider phobics but not for the snake phobics. Interestingly, the same negative correlation was found for self-rated anxiety. Putting the findings together we can surmise that the repressive activity begins downstream from its perceptual registration. Not too surprising, but a start. Perhaps the newer imaging procedures such as the fMRI would make it possible to identify with more precision the brain elements involved. We are at present exploring the possibility of a related study using the pop/look paradigm to investigate unconscious inhibition in collaboration with Daniel Glaser at the Institute for Cognitive Neuroscience, University College, London. 


\section{QUALITATIVE DIFFERENCES BETWEEN CONSCIOUS AND UNCONSCIOUS PROCESSES}

In the subliminal research literature the interest in qualitative differences between conscious and unconscious processes emerged from a methodological dilemma: since most studies as already noted were conducted at the subjective threshold so that phenomenal consciousness could not be ruled out, the argument is made that if qualitative differences were found between the presumed subliminal effect and conscious performance then it could be inferred that the effects were truly subliminal. As Snodgrass (2005a) has pointed out, the argument is far from convincing because the qualitative differences could characterize phenomenal as opposed to reflective awareness. And in fact, in a study in which the role of reflective awareness wss heightened qualitative differences disappeared (Visser \& Merikle 1999). The qualitative differences I will now describe are primarily of theoretical relevance, although they also possess methodological implications.

In order to better appreciate the nature of these qualitative differences I will need to sketch briefly a theoretical frame of reference based largely on the thinking of Charles Fisher, a pioneer in psychoanalytically inspired subliminal research. In an article published in 1957, Fisher presented a model in which there was one essential assumption: That all stimuli registered initially at a preconscious level. Certainly since then a considerable amount of evidence has accumulated in support of this assumption Cognitive processes such as categorization, for example, can occur prior to consciousness. Fisher contended that once registered preconsciously that a stimulus can undergo different fates: 1 . most usually it is delivered directly into consciousness with very little modification, in particular if it is of sufficient intensity, 2. it could remain pre-conscious if, for example, it were not of immediate attentional interest, 3. it could become associated with anxiety-arousing significance because of some link to unconscious conflict and be inhibited from entry into consciousness. These three factors, stimulus intensity, attention, and unconscious significance act independently of each other and can strengthen, weaken, or cancel each other. Thus, as Brakel (1989) has illustrated from clinical experience and as Spiegel, Cutcomb, Chuen \& Pribram (1985) have shown through hypnosis, a highly intense stimulus which would ordinarily quickly become conscious can be kept from consciousness by a more powerful unconscious motivation and 
result in a negative hallucination- the absence of conscious perception in the face of a clear sensory presence.

When a subliminal stimulus registers preconsciously it lacks sufficient stimulus intensity to follow immediately the path to consciousness. Yet it is has entered through a perceptual pathway, is encoded, and much evidence indicates can have various indirect effects on consciousness. Perhaps the clearest examples are provided by priming effects. In some instances, as in our pop/look experiments, stimulus itself enters consciousness in the form of a correct guess. It is this latter finding which is of special interest with respect to qualitative differences. Although it is true that the correct guess enters consciousness, there is one significant quality it lacks - that of being experienced as a perception even though it has registered through a perceptual channel. Yet only its contents enter consciousness and in different form..

One might ask why the subject does not have a perceptual experience, exclaiming, "Oh, yes that was the word just flashed". The answer appears to be obvious, but is nevertheless of central importance: There is no such conscious experience of a perception because it was never in consciousness to start with. From this it is possible to infer that the process of becoming conscious contributes to an important and necessary function generally overlooked in the literature on consciousness. In order to appreciate the nature of this function I will need to distinguish between a representation and what I will call its mental vehicle. A representation of a cat can appear in consciousness as a perception, a memory, an image, a thought, part of a fantasy, and so on. These are all mental vehicles in which, if you like, the same representation can take a ride at different times. Remarkably, we do not seem to have any trouble most of the time in distinguishing a representation from its vehicle. We know when we are experiencing a perception, an image, a memory, or a thought even though the content may be identical. Put differently, in each case the vehicle as a mental act is about something in Brentano's sense of intentionality, that something is the representation or content. What I am proposing is that the process of becoming conscious confers this vehicular tag. When stimuli enter preconsciously and therefore have not as yet participated in the process of becoming conscious they lack that tag and thus can readily be confounded with images, memories, thoughts, or other mental vehicles. The experience of the correct guess in subliminal experiments comes as something equivalent to a thought, or a possibility, not of a perception or memory. Given the task it is not difficult to see that this thought is called a guess. 
There is one other related hypothesis: Even though once conscious a representation has been tagged with its mental vehicle it can lose its tag if it drops out of consciousness as a result of repression. In the repressed, or dynamic unconscious, representations have lost their vehicle tag and thus for example, perceptions and memories can be confounded accounting for the apparent timelessness of the dynamic unconscious. This theory has been presented at greater length elsewhere (Shevrin 1986, 1998).

With these conceptual tools in hand I would like now to address the issue of qualitative differences between conscious and unconscious processes as they apply to the research I have thus far cited.

I have already described findings bearing on one such potential qualitative difference: there is a different relationship between conscious and unconscious processes as a function of stimulus detectability. Here we come across the first stumbling block. I have argued that whether d' is above or below the mean in experiments below the objective detection threshold, the stimuli are still unconscious, or perhaps more consistent with the terminology just introduced, are still preconscious. Then why should above and below d' scores relate differently to conscious guessing? And moreover, why should they be correlated with repression? Presumably according to the hypotheses just advanced they all lack the conscious memory tag.

The problem can be addressed by conceptualizing conscious tagging as a process that is continuous rather than categorical. As d' increases the representation involved becomes closer to the threshold of consciousness, and takes on more of a perceptual tag. Prior to consciousness the tagging is not either or, but one of degree. Once conscious however it becomes fully tagged. An analogy from the old days of home photography might be helpful. In developing a print the negative was first bathed in a solution that begins to bring out the light and dark exposed areas so that one can begin to make out forms, but if one were to take the negative out of the solution at that point the emerging light and dark patterns would gradually disappear. Instead one bathes the developed negative in a fixing solution that completes the printing process. Similarly as d' progresses above zero it is developing as a perception, but only after it enters consciousness is it fixed or tagged as a perception. It is also possible to imagine that the binding process by which individual features are bound together to form an object may be another analogue if not a case in point for the development of a perceptual tag. 
For the lookers in the look strategy to the extent that d' is above the mean to that extent the correct stimulus is assuming more of a perceptual character. Since at no point has thelooker had a fully conscious experience of the stimuli, this is at variance with the looker's conscious experience that there was nothing to be see. The correct response is rejected. On the other hand, to the extent that d' is below the mean it lacks a perceptual tag and presents no inconsistency with what is experienced consciously. It is therefore more likely to be accepted as a guess by lookers.

For the repressors, who responded in the same way as lookers, the outcome is the same but the means used are different. This difference can best be illustrated by the result from the social phobia experiment. In that experiment repressors showed the greatest difference in favor of subliminal over supraliminal differentiation of unconscious conflict words. When the unconscious conflict words were presented supraliminally they possessed sufficient stimulus intensity to enter consciousness as perceptions. But the brain responses tell us that they were not differentiated from the other three sets of words as they had been subliminally. They no longer were experienced as different from the other words.

As suggested previously repression removes the mental tags from representations. Once this happens a different mode of thinking becomes possible. Since perceptions, memories, fantasies no longer exist as discrete mental categories it is possible for representations initially linked to a particular mental category to meld and flow together creating the conditions for condensations and displacements, both mechanisms of what Freud referred to as the primary process. In another series of experiments we have identified two formal properties of categorization which distinguish between this primary process melding of representations and the more discrete, rational form of categorization characterizing what Freud referred to as the secondary process. It would take me well beyond my time allotment to describe these studies and their implications for understanding further qualitative differences characterizing the interaction of conscious and unconscious processes. Fortunately, my colleague Dr. Brakel has presented this research in some detail in her chapter for the volume Psychanalyse im Dialog der Wissenschaften. Anglo-amerikanische Perspektiven (Brakel 2004, in Giampieri-Deutsch 2004). 


\section{CONCLUSIONS}

I will now return to the four propositions stated at the beginning of this chapter and see how the findings described in the body of my contribution support them.

1. Consciousness cannot be fully understood without knowledge of unconscious processes.

The findings most relevant to this proposition are provided by the social phobia study in which the patients during the supraliminal presentation of the unconscious conflict words consciously experience simply perceiving words familiar to them. But their brain responses and the HOQ tell us a different story. The unconscious conflict words are being less well differentiated from the other words than they had been subliminally, and the extent to which this happens is a function of an unconscious inhibition. The state of affairs is often the case clinically, in particular during the early phases of treatment when neither patient nor analyst is aware of the special significance of certain communications, although the same inhibitory processes are at work as revealed later in the treatment.

2. Unconscious processes are complex, representational, highly interactive with conscious processes and not dispositional or latent.

Again the social phobia study can best speak to this proposition. An unconscious conflict is a complex organization of perceptions, memories, feeling, fantasies and desires centered around significant people both past and present in the individual's life. In these respects they are as complex and representational as conscious processes. The unconscious conflict words selected by the psychoanalysts constitute a sampling of these complex representations and their interrelationships. They are thus representations in their own right as well as complex. Because of the persistence of these unconscious conflicts hypothesized to cause the social phobic symptom, they are active and influence ongoing conscious processes. This is evidenced by what has already been said with respect to the first proposition. When the complex representations of the unconscious conflict are presented supraliminally, their unconscious significance influences the fate of these representations in consciousness.

3. The interaction between conscious and unconscious processes can best be understood when person and context are taken into account.

Evidence for this proposition is provided by both the pop/look studies and the social phobia study. If context in the form of different strate- 
gies and individual differences in the form of strategy preferences had not been included in the series of pop/look studies no subliminal effects would have been found. In the social phobia study this is further supported by the use of unique, personally meaningful words, a considerable departure from most cognitive experiments in which generally the same stimuli are used for all subjects. Nevertheless, only through the use of these personally meaningful words was it possible to discover a functional relationship true for all of the subjects. The time to consciousness study also revealed the importance of individual differences; once taken into account an interesting finding emerged concerning the relationship to repression.

4. Quantitative and qualitative differences between conscious and unconscious Processes.

The results bearing on the relationship between stimulus intensity and different thresholds indicate that quantitative and qualitative factors are closely intertwined. At the objective detection threshold whether one is above or below the d' mean, an unconscious quantitative factor, determines whether one will facilitate or inhibit under certain conscious task instructions, a qualitative factor. It is also important to keep in mind that while measured as a quantity, $d$ ' itself is associated with an important qualitative feature. As d' rises above zero it assumes more of a perceptual tag; as d' falls below zero it ends to lose its perceptual tag. At higher and higher levels of d' the stimulus begins to acquire a perceptual character until at the subjective threshold they enter phenomenal consciousness as perceptions. It was further suggested that consciousness confers a mental vehicle tag on a representation so that the representation is identified as a perception, memory, image, fantasy, etc., and that repression undoes this tagging so that repressed representations can flow and meld across mental vehicles producing the condensations and displacements identified by Freud with the primary process.

These propositions taken together make possible a different approach to conceptualizing the nature of consciousness and its relationship to unconscious processes from that currently prevailing in much research and theorizing in the field. For example, from this standpoint, unconscious effects are neither simple nor evanescent as has been advanced recently. As the audience seated in front of the visible theater we are challenged to figure out what is happening on the other stage if we are to understand what is going on before us. As a psychoanalyst this has always been the clinical challenge. Fortunately we now have experimental methods taking us beyond the limitations of the clinical set- 
ting that allow us to look more directly on what is happening on the invisible stage and in this chapter I have tried to emphasize what we have learned from these more direct observations.

\section{REFERENCES}

Ayckbourn, A. (2000). Home \& Garden. London: Faber \& Faber.

Baars, B (1997). In the Theater of Consciousness: The Workspace of the Mind. New York: Oxford University Press.

Bernat, E., Bunce, S. \& Shevrin, H. (2001). Event-related potentials differentiate positive and negative mood adjectives during both supraliminal and subliminal visual processing. International Journal of Psychophysiology 42: 11-34.

Bernat, E., Shevrin, H. \& Snodgrass, M. (2001). Subliminal visual oddball stimuli evoke a P300 component. Journal of Clinical Neurophysiology 112: 159-171.

Block, N. (1995). On a confusion about a function of consciousness. Behavioral and Brain Sciences 18: 227-287.

Bock, G.R. \& Marsh, J., ed. (1993). Experimental and Theoretical Studies of Consciousness. CIBA Foundation Symposium 174. Chichester: Wiley.

Brakel, L.W. (1989). Negative hallucinations, other irretrievable experiences and two functions of consciousness. International Journal of Psychoanalysis 46: 461-479.

Brakel, L. (2004). Der Primärvorgang: Experimentalle Belege für A-rationale Organisationsprinzipien und einen philosophischen Fall von A-rationaler Referenz. In Psychoanalyse im Dialog der Wissenschaften. Vol. 2. Angloamerikanische Perspektiven, ed. P. Giampieri-Deutsch. Stuttgart: Kohlhammer, pp. 143-167.

Brewer, M.B. \& Luce, R.D. (1998). Basic research in cognitive science. American Psychological Society Observer, Report 6: 3-39.

Caine, T.M. \& Hawkins, L.G. (1963). Questionnaire measure of the hysteroid/obsessoid component of personality: The HOQ. Journal of Consulting Psychology 27: 206-209.

Edelman, G. (1987). Neural Darwinism: The Theory of Neuronal Group Selection. New York: Basic Books.

Fisher, C. (1957). A study of the preliminary stages of the construction of dreams and images. Journal of the American Psychoanalytic Association 5: 60-67.

Friston, K. J. (2000). Imaging neuroscience: 1. Neuronal transients and nonlinear coupling. Philosophical Transactions of the Royal Society of London B 355: 215-236.

James, W. (1890). Principles of Psychology. New York: Holt

Kandel, E. R. (1999). Biology and the future of psychoanalysis: A new intellectual framework for psychiatry revisited. American Journal of Psychiatry V.156(4): 505-524.

Libet, B., Alberts, W.W., Wright, E.W., Delattre, L.G., Levin, G. \& Feinstein, B. (1964). Production of threshold levels of conscious sensation by electrical stimulation of human somatosensory cortex. Journal of Neurophysiology 27: $546-578$. 
Ludolph, P.S. (1981). The dissociative tendency, its relationship to personality style and psychopathology. Unpublished doctoral dissertation. Ann Arbor: University of Michigan.

Shevrin, H. (1986). A proposed function of consciousness relevant to theory and practice. Presented at the American Psychological Association Convention, Washington, D.C., August 22, 1986.

Shevrin, H. (1998). Why do we need to be conscious? A psychoanalytic answer. In Advanced Personality, ed. D.F. Barone, M. Hersen \& V.B. Van Hasselt. New York: Plenum Press.

Shevrin, H., Bond, J.A., Brakel, L.W., Hertel, R.K. \& Williams, W.J. (1996). Conscious and Unconscious Processes: Psychodynamic, Cognitive, and Neurophysiological Convergence. New York: The Guilford Press.

Shevrin, H., Ghannam, J. \& Libet, B. (2002). A neural correlate of consciousness related to repression. Consciousness and Cognition 11: 334-341.

Shevrin, H., Williams, W. J., Marshall, R.E., Hertel, R.K., Bond, J.A. \& Brakel, L.W. (1992). Event-related potential indicators of the dynamic unconscious. Consciousness and Cognition 1: 340-366.

Snodgrass, M. (2005a). Disambiguating conscious and unconscious influences: Do exclusion paradigms demonstrate unconscious perception? American Journal of Psychology, in press.

Snodgrass, M. (2005b). Unconscious Perception: Theory, Method, and Evidence. Philadelphia: John Benjamins, in press.

Snodgrass, M., Bernat, E. \& Shevrin, H. (2005). Unconscious perception models. Perception and Psychophysics, in press.

Snodgrass, M., Shevrin, H. \& Kopka, M. (1993). The mediation of intentional judgments by unconscious perceptions: The influence of task strategy, task preference, word meaning, and motivation. Consciousness and Cognition 2: 169-193.

Spiegel, D., Cutcomb, S., Chuen, R. \& Pribram, K. (1985). Hypnotic hallucination alters evoked potentials. Journal of Abnormal Psychology 94: 249-255.

Van Selst, M. \& Merikle, P. (1993). Perception below the objective threshold? Consciousness and Cognition 2: 194-203.

Visser, T. \& Merikle, P. (1999). Conscious and unconscious processes: The effects of motivation. Consciousness and Cognition 8: 94-113. 